\title{
POLÍTICA, SOCIEDADE E LINGUA EN GALICIA
}

Fermín Bouza

Universidad Complutense de Madrid 



\section{UNHA LONGA HISTORIA DE INTOLERANCIAS QUE SE QUERE CHAMAR LIBERDADE}

O 23 de xuño de 2008 presentábase no Ateneo de Madrid un chamado Manifiesto por una lengua común $n^{1}$ de gran resonancia nos medios de comunicación e punto principal de partida dunha crecente presión sobre as linguas periféricas e, no noso caso, sobre o galego, que é vista no ollo dese furacán madrileño como unha das linguas que tratan de varrer do mapa o castelán e de «imporse» aos nenos e á poboación en xeral. Ao seren os promotores deste asunto, en liñas xerais, xentes decentes e demócratas recoñecidos, é probable que a culpa deste abuso sexa nosa, das persoas periféricas e dos políticos daquel momento, e tamén das nosas linguas, que se atreven contra todo sentido común a aspirar a seren as linguas dos nosos países e a non morreren. Esa aspiración concrétase en diversas políticas de reinstalación do galego na sociedade civil galega, en particular no ensino, e esas políticas poden desprazar o idioma castelán nalgunha porcentaxe de materias ou doutro xeito. Hai que dicir que practicamente todo o mundo coñece e fala o castelán, e que esta lingua non corre o menor perigo en Galicia, que está cruzada, como as demais nacionalidades, de libros, películas, televisións, radios, etc., en castelán, mentres en galego presenta unha absoluta e ridícula minoría destas cousas. Isto, porén, non parece conmover os asinantes do manifesto, cuxa razón exemplar comeza a diluírse en canto observamos os feitos reais e as cifras reais. É posible que non anden moi ben informados sobre estas cousas, sen descartar que os problemas dos demais lles importen pouco e os seus lles importen excesivamente. Pero isto non sería coherente con certo civismo (tamén o teño chamado decencia e democracia). Pero realmente o castelán está perseguido, decae, e os seus falantes carecen de dereitos? As razóns que se expoñen non só son falsas: son absurdas e parecen inventadas para deslexitimar as nosas linguas nacionais e a nós mesmos como per-

${ }_{1}^{1}$ http://www.elpais.com/articulo/espana/Manifiesto/lengua/comun/elpepuesp/20080623elpepunac_29/Tes 
soas que as defenden do que, a xuízo de moitos e sobre os datos coñecidos, parece a caída final de tales linguas opresoras de dereitos a través dos seus «fanáticos» (esta palabra foi usada por Carmen Iglesias, que advertiu que «o fanatismo» neste asunto vai acompañado dunha historia falseada que nos fai retroceder ao século XVIII) $)^{2}$.

Pero, moi ao contrario do que denuncia esa tremenda agresividade dos gardiáns das esencias patrias, libertarias e democráticas, a realidade é moi teimuda cos feitos, e a verdade é exactamente a oposta: unha lingua de estado, o castelán, vai desprazando pola propia dinámica económica e polas paralelas presións políticas ou represións a tales linguas periféricas, que no momento actual mos-

2 As razóns deste uso, ademais de no texto do manifesto, poden amplialas nesta crónica. http://www.elpais.com/articulo/espana/veintena/intelectuales/reclama/reformas/defender/castellano/ elpepiesp/20080624elpepinac_8/Tes: Una veintena de intelectuales ha promovido un manifiesto en defensa del castellano que fue presentado ayer en el Ateneo de Madrid y que reivindica la importancia de esta lengua y reclama una normativa legal — "que puede exigir una modificación constitucional y de los estatutos»para garantizar los derechos de los españoles que quieran expresarse y estudiar en castellano, "única lengua común en todo el territorio». Los promotores del Manifiesto por la lengua común llamaron ayer a la sociedad civil a la movilización, "a hacer cosas", porque, señalaron, «los partidos van un poco por detrás» en este asunto. «El documento arranca con una conclusión lapidaria: "Desde hace algunos años hay crecientes razones para preocuparse en nuestro país por la situación institucional de la lengua castellana”. Y solicita al Parlamento "una normativa legal de rango adecuado para fijar inequívocamente" que "la lengua española es común y oficial en todo el territorio nacional", que los ciudadanos que lo deseen tienen el derecho de ser educados en lengua castellana y atendidos en las dos lenguas oficiales, o que los funcionarios no están obligados a utilizar la lengua autonómica. El manifiesto señala que ninguna lengua "tiene derecho a conseguir coactivamente hablantes, ni imponerse como prioritaria en la educación”.

El filósofo Fernando Savater, que en el acto de presentación ejerció de maestro de ceremonias, subrayó que "una cosa es incentivar el conocimiento de las lenguas autonómicas y otra imponerlas a costa de la lengua común". Y señaló que "la discriminación" de los ciudadanos castellanohablantes en comunidades con dos lenguas oficiales "perjudica a los más desfavorecidos, como los inmigrantes, dañando sus posibilidades sociales y laborales”. Por eso, Savater pidió que ningún idioma autonómico sea lengua vehicular en la educación — como ocurre en Cataluña y se ha propuesto en el País Vasco - sino que también pueda elegirse el castellano. El filósofo estuvo flanqueado por Carlos Martínez Gorriarán, miembro de la dirección de Unión Progreso y Democracia (UPyD), la historiadora Carmen Iglesias y el escritor Álvaro Pombo, en un acto al que asistieron unas 70 personas. Ayer ya anunciaron su adhesión el Foro Ermua y la Asociación Galicia Bilingüe. Entre los promotores del manifiesto también están Mario Vargas Llosa, José Antonio Marina y Albert Boadella. Carmen Iglesias advirtió de que "el fanatismo" en este asunto "va acompañado de una historia falseada que nos hace retroceder al siglo XVIII". Y Savater acusó a los partidos de "todos los colores" de haber jugado siempre con este tema y no haberlo planteado "de forma seria". Rosa Díez, diputada de UPyD, afirmó que presentará una iniciativa en el Congreso encaminada a evitar "la discriminación de los ciudadanos" por razones lingüísticas. Los promotores del manifiesto invitaron a los ciudadanos a adherirse a él en la web de UPyD (www.upyd.es)». 
tran unha situación agónica que esixe reaccionar e elaborar leis recuperacionistas de acordo, entre outras cousas, coa Carta europea das linguas rexionais ou minoritarias, firmada polo Reino de España coa data do 9/4/2001 e que entrou en vigor o 1/8/2001, e á que España se debe.

De feito, é agora cando é posible tomar algunha medida a prol do galego. Antes disto, o castelán foi o único idioma realmente existente na burocracia do Estado. Que as primeiras medidas recuperacionistas atopen tal eco entre eses intelectuais explica por si mesmo moitas caras do fenómeno reactivo. O feito de que as teses políticas históricas contra as linguas periféricas do Estado central se traten de converter agora en teses en defensa dos dereitos humanos fala dun cinismo institucional que chega aos mesmos cidadáns que o seguen. Aquí, no noso país, non houbo máis represión e máis marxinación ca a do idioma galego. E tampouco se trata agora de mudar os termos: o castelán ten, e segue a ter, a prioridade social propia de quen manda dende hai moitos séculos, ademais de ter as leis oportunas ao seu favor como lingua oficial do Estado (co deber de coñecela, cousa que non pasa coas outras linguas que din españolas).

As políticas lingüísticas recuperacionistas teñen como obxectivo a recuperación social plena do uso das linguas, con particular insistencia no caso de antigas nacións (con estado / sen estado) que hoxe coexisten con outras no marco de estados-nación, como é o caso de Galicia no Reino de España. Esta dinámica recuperacionista foi posible grazas á recuperación da democracia no Estado español e ao traballo de partidos e organizacións sociais a prol desas linguas.

Quizais nunca como agora as linguas do Estado español en xeral e a galega en particular foron obxecto de tanta atención polos poderes públicos, os partidos políticos, as organizacións civís e, sobre todo, pola prensa. A atención mediática vai incorporando ao que os sociólogos chamamos a «axenda mediática», o tema lingüístico das comunidades autónomas. Os temas autonómicos en xeral ocupan o $23 \%$ da axenda mediática ${ }^{3}$ (dende setembro de 2008 ata setembro de 2009), e esta é unha cifra importante. Nesa porcentaxe non é menor a cuestión lingüística, que cruza, co seu nome ou co doutros subtemas, toda a problemática autonómica.

\footnotetext{
3 Datos do Grupo de Investigación «Agenda y voto» (Juan Jesús González, Palmira Chavero, Antón R. Castromil, Raquel Rodríguez e eu mesmo) de varias universidades.
} 
Pero non sempre se miran con bos ollos as nosas linguas. Xa vimos o Manifiesto. No congreso de UPyD (Rosa Díez é a líder dese partido, a mesma que logo dirá aquilo de "gallego en el buen sentido de la palabra» a Iñaki Gabilondo en $\mathrm{CNN}+$ ) hai unha proposta que di (transcrito da prensa) ${ }^{4}$ : «UPyD aboga por suprimir el artículo 3.3 de la Carta Magna, que reza que "la riqueza de las distintas modalidades lingüísticas será objeto de especial respeto y protección”, y por incluir la palabra "lengua" en el artículo 14, de forma que los españoles no puedan ser discriminados por razón de nacimiento, raza, sexo, religión y opinión, pero tampoco por la lengua».

Lembremos o artigo 3 da Constitución:

1. El castellano es la lengua española oficial del Estado. Todos los españoles tienen el deber de conocerla y el derecho a usarla.

2. Las demás lenguas españolas serán también oficiales en las respectivas Comunidades Autónomas de acuerdo con sus Estatutos.

3. La riqueza de las distintas modalidades lingüísticas de España es un patrimonio cultural que será objeto de especial respeto y protección.

E lembremos tamén o Estatuto de autonomía de Galicia:

Artigo quinto.-

Un. A lingua propia de Galicia é o galego.

Dous. Os idiomas galego e castelán son oficiais en Galicia e todos teñen o dereito de os coñecer e de os usar.

Tres. Os poderes públicos de Galicia garantirán o uso normal e oficial dos dous idiomas e potenciarán o emprego do galego en todos os planos da vida pública, cultural e informativa, e dispoñerán os medios necesarios para facilitar o seu coñecemento.

Catro. Ninguén poderá ser discriminado por razón de lingua.

Neste momento, en Galicia, e tras pasar por moitos e variados momentos logo das eleccións autonómicas de 2009, o partido gañador (con menos votos

${ }^{4}$ http://www.libertaddigital.com/sociedad/upyd-pide-eliminar-de-la-constitucion-la-defensa-del-plurilinguismo-1276375600/ 
ca o conxunto de perdedores, pero un escano máis, téñase presente este dato) vén de aprobar e sacar no DOG (25/05/2010) un novo decreto sobre a lingua que cambia negativamente o proceso recuperacionista e volve a un pasado previo ao propio goberno do PP en Galicia. No medio, manifestacións e mobilizacións cidadás que non fan mudar ao goberno o seu criterio, un criterio que non teño máis remedio que chamar liquidacionista: é un decreto para pór fin ao galego nas cidades, definitivamente.

De feito, o novo decreto fai desaparecer o galego no ensino na etapa preescolar (infantil) ata os 6 anos en medios maioritariamente castelanfalantes, que son todos os urbanos, ao deixar como prioritaria a chamada «lingua predominante entre o alumnado» (maioritaria):

Artigo $5^{\circ}$.- Educación infantil.

$\mathrm{Na}$ etapa de educación infantil, o profesorado usará na aula a lingua materna predominante entre o alumnado, ben que deberá ter en conta a lingua do contorno e procurará que o alumnado adquira, de forma oral e escrita, o coñecemento da outra lingua oficial de Galicia dentro dos límites da etapa ou ciclo.

A lingua materna predominante do alumnado será determinada polo centro educativo de acordo co resultado dunha pregunta que se efectuará aos pais, nais, titores/as ou representantes legais do alumno/a antes do comezo do curso escolar acerca da lingua materna do seu fillo ou filla.

Atenderase de xeito individualizado o alumnado tendo en conta a súa lingua materna. Cada centro educativo deberá facer constar no seu proxecto lingüístico as actividades e estratexias de aprendizaxe empregadas para que o alumnado adquira, de forma oral e escrita, o coñecemento das dúas linguas oficiais.

Só ese artigo 5.1 do novo decreto é suficiente para afastar do galego, como mínimo, o $50 \%$ da poboación. E afastalo para sempre: négaselles aos cativos a integración no galego como lingua básica e cognitiva dende a infancia. Que di a Carta europea das linguas rexionais ou minoritarias sobre o ensino preescolar (0-3-6 anos)?

\section{Artigo 8.1:}

En materia de ensino, as partes comprométense, no que fai ao territorio sobre o que esas 
linguas son practicadas, segundo a situación de cada unha desas linguas e sen prexuízo do ensino da(s) lingua(s) oficial(ais) do Estado:

- a prever unha educación preescolar asegurada nas linguas rexionais ou minoritarias en cuestión; ou

- a prever que unha parte substancial da educación preescolar sexa asegurada nas linguas rexionais ou minoritarias en cuestión.

\section{Os propios membros da Carta, como Simone Klinge, do seu secretariado, falan claramente dos incumprimentos do novo goberno galego de Feijóo e, xa que logo, do mesmo Estado: «España non cumpre o que firmou»s.}

${ }^{5}$ Daniel Salgado, en El País-Galicia (23/02/2010): «La Xunta incumple el tratado europeo de lenguas regionales. Los expertos de la UE analizarán en abril la política de Feijóo. El Gobierno de España ratificó en 2001, bajo la presidencia de José María Aznar, la Carta Europea de las Lenguas Regionales y Minoritarias. El documento, impulsado en 1992 por el Consejo de Europa y con rango de tratado internacional, fue aprobado por las Cortes en su versión de más elevada protección para "lenguas reconocidas como oficiales en los Estatutos de Autonomías de País Vasco, Cataluña, Islas Baleares, Galicia, Valencia y Navarra". Entre los compromisos que entonces adquirió el Estado se encuentra la "garantía de una educación en las lenguas regionales o minoritarias correspondientes" en todos los niveles del sistema público de enseñanza. Ayer, en Santiago, la miembro del secretariado de la Carta, Simone Klinge, afirmó que España "no cumple con los compromisos que firmó" entonces. El secretariado vela por la aplicación del texto y pertenece al Consejo de Europa. Klinge expuso su parecer en las jornadas de análisis sobre el documento organizadas por el Consello da Cultura Galega. En respuesta a una pregunta del público asistente al seminario, la experta en sociolingüística del Consejo recordó el grado que los preceptos ratificados en su día por España implican, entre otras obligaciones, "la existencia de una educación íntegramente en gallego". La ponente, acompañada por el secretario del Consello da Cultura y sociolingüista Henrique Monteagudo, aseguró que "impartir en gallego un 50\% de las clases" no encaja con los niveles del tratado asumidos por España en 2001, por lo menos en lo referente a la educación. Del seguimiento de la Carta se encarga un comité de expertos dependiente del Consejo de Europa. El último informe emitido data de diciembre de 2008 y en él los especialistas destacaban el decreto de las lenguas del Gobierno bipartito que propugnaba una carga lectiva en gallego de, al menos, la mitad de las asignaturas. También señalaban la necesidad de establecer programas educativos con el gallego como lengua vehicular y elogiaba el proyecto de las galescolas, escuelas infantiles con el gallego como idioma vehicular. El texto valoraba, de modo general, las políticas lingüísticas desarrolladas hasta aquel momento con cierto pesimismo: "En el sector de la enseñanza en particular, a pesar de las interesantes iniciativas emprendidas por las autoridades, el número de alumnos que reciben educación escolar en gallego sigue siendo muy bajo". Las medidas adoptadas por el Ejecutivo de Alberto Núñez Feijóo en materia lingüística han derogado la normativa de la Xunta de Emilio Pérez Touriño y eliminado el proyecto de las galescolas. El comité de expertos volverá a reunirse en abril, apuntó Simone Klinge. Entonces analizará "con cuidado" los primeros pasos de la política lingüística del Gobierno de Feijóo. Las sesiones del Consello da Cultura sobre la Carta Europea de las Lenguas Minoritarias continúan hoy. Hablarán profesores de universidades escocesas, galesas y catalanas». 
Con posterioridade, apareceu a nova de que se prohibía a inmersión voluntaria en áreas castelanfalantes ${ }^{6}$ para preparar os nenos para a seguinte etapa do ensino, onde entrarían sen a menor formación galega. Todo isto vai contra as leis pero, sobre todo, vai contra o sentido común e non augura nada bo para a nosa terra en ningún ámbito.

Non vou afondar nestes matices legais e nestes absurdos que foron amplamente comentados polos informes do Consello Consultivo de Galicia, polo informe do Consello Escolar de Galicia, polo informe da Real Academia Galega e polo informe do Consello de Cultura Galega, cando menos ${ }^{7}$. E todos de xeito negativo tanto para os textos-borrador do decreto como para o mesmo decreto, segundo e como e da cuestión da que se trate.

É un decreto que nace sen máis apoios que os que lle presta a maioría de goberno (un escano) ao actual partido no goberno. Quizais a miña tarefa de sociólogo sexa a de falar en termos sociais e reais do galego e dos seus problemas no medio destas continuas malas novas que se lle veñen enriba.

Creo, e de aí o título deste apartado, que unha longa historia de intolerancia, que marcou fortemente a construción do que hoxe chamamos o Reino de España, é a principal causa da desaparición das linguas que aquí chamo periféricas. Intolerancia, ignorancia, barbarie, que se fan presentes de xeito teimudo no Reino devandito con moita frecuencia. Se os intelectuais cualificados que asi-

6 http://www.vieiros.com/nova/80000/educacion-prohibe-os-programas-infantis-de-inmersion-nas-cidades: «Educación prohibe os programas infantís de inmersión nas cidades. A consellaría comunicoulles a 47 centros educativos que non poderán continuar con este modelo de aulas no vindeiro curso, aínda que os pais as demanden. $\mathrm{O}$ decreto aprobado polo bipartito permitía a inmersión lingüística en galego en educación infantil nas contornas urbanas, como medida para favorecer que os máis pequenos que teñen un contacto nulo co idioma do país o puidesen ter nas escolas. Esta posibilidade existía grazas á lexislación aprobada en 1995 polo goberno Fraga e que posteriormente foi desenvolta no decreto de 2007. Algúns colexios de ámbitos castelanfalantes (por acordo da comunidade educativa) podían potenciar este modelo para garantir unha competencia mínima en galego dos rapaces de entre tres e cinco anos. O Sindicato de Traballadores do Ensino de Galiza (STEG) lembra que xa o ano pasado a consellaría optou por eliminar as axudas económicas para este programa. Agora, Educación acaba de comunicarlles a 47 centros que mantiñan estes programas de que non poderán levarse a cabo no vindeiro curso. Dende o STEG aseguran que "esta decisión non ten en conta a demanda constante de numerosas familias que constatan diariamente a imposibilidade de garantir o bilingüismo para unhas nenas e uns nenos que, a partires dos 6 anos, terán que coñecer ben o galego para comezar o ensino obrigatorio"».

7 No Centro de Documentación Sociolingüística do Consello da Cultura Galega pódense consultar moitos ou todos os documentos citados: http://www.consellodacultura.org/arquivos/cdsg/ 
nan ese Manifiesto pensan así, como non pensará o pobo non ilustrado sobre a mesma cousa? O drama dun estado non moi ben estruturado reflíctese nestas liortas babecas arredor do obvio.

Tamén é certo, xaora, que a modernización de Galicia se fai en castelán, pola propia inserción de Galicia nun proceso económico de dependencia que ten unha lingua dirixente, o castelán, que non é exactamente unha lingua franca, isto sería falso así dito: é unha lingua forzosa e forzada, o produto dunha historia moi negativa para o noso país. Nesas condicións, as actitudes destes intelectuais e de moitos outros, a través do tempo da infamia, na liña de denunciar os «abusos» dos máis febles, non é máis ca unha guinda aceda no acedo pastel ou, mellor, o tiro de graza a un predefunto. Nunca faltaron axudantes para o matachín, unhas veces por ignorancia e outras por mala fe ou por boa fe mal informada, que vén a ter as mesmas consecuencias. $\mathrm{O}$ caso é que aquí andamos unha vez máis, e loitando, unha vez máis tamén, polo que é obvio, na liña que desesperaba a Dürrenmatt: os nosos dereitos como pobo e como individuos. Os nosos dereitos, sen máis. E cando digo os nosos digo os de todos: o trato xusto e cabal para todos, dende a ciencia e o sentido común, dende a Política, no sentido máis histórico e cívico do concepto.

\section{OS DATOS CIS / IGE}

Vou traballar neste artigo a partir dos datos de 2008 do Instituto Galego de Estatística (IGE) —a Enquisa de condicións de vida das familias. Coñecemento $e$ uso do galego. Ano 2008 , cunha mostra ampla (10 272 vivendas) e complexae os de 2009 do Centro de Investigaciones Sociológicas (CIS), e deixar agora os datos importantes e con mostras relevantes do Mapa sociolingüístico de Galicia 2004 (moi debatidos) e do Mapa sociolingüistico de Galicia 1994. Vou primar a actualidade para favorecer un punto de vista actualizado, non sendo este un estudo histórico ou comparativo.

No referente aos datos do CIS (Preelectoral e Postelectoral 2009 das eleccións autonómicas galegas ${ }^{9}$ ), teño publicado xa, tanto no meu blog como en diversas

\footnotetext{
${ }^{8} \mathrm{http}: / /$ www.ige.eu/web/mostrar_actividade_estatistica.jsp?idioma=gl\&codigo=0206002001

${ }^{9}$ Estudos CIS 2783 e CIS 2796.
} 
publicacións espalladas en diversos formatos, un conxunto de datos que comezarán a saír axiña de xeito ordenado e sistemático. A maior parte deles organízanse arredor da pregunta sobre a lingua inicial:

¿Podría decirme, por favor, cuál es su lengua materna, es decir, aquella que aprendió de niño en casa?

Esta pregunta é a 25 no estudo preelectoral e a 39 no postelectoral. Comparemos as respostas:

- Táboa $1^{10}$

\begin{tabular}{|c|c|c|}
\hline $\begin{array}{l}\text { ¿Podría decirme, por favor, cuál es su } \\
\text { lengua materna, es decir, aquella que } \\
\text { aprendió de niño en casa? } \\
\text { (enunciados e categorías CIS) }\end{array}$ & $\begin{array}{l}\text { Preelectoral CIS (2783; } \\
\mathrm{n}=2998 ; \text { p. 25) }\end{array}$ & $\begin{array}{l}\text { Postelectoral CIS (2796; } \\
\mathrm{n}=2996 ; \text { p. 39) } \\
\text { Con probable indicación ou lectura } \\
\text { explícita da opción «las dos lenguas» }\end{array}$ \\
\hline Español (castellano) & 30 & 24,9 \\
\hline Gallego & 55,6 & 50,3 \\
\hline Se hablaban las dos lenguas & 13,1 & 24,2 \\
\hline Otros idiomas & 1,1 & 0,5 \\
\hline
\end{tabular}

Pode verse que se devolvemos para español e galego as porcentaxes que se van no Postelectoral a «las dos lenguas» (só a indicación ou lectura explícita da opción que agora medra pode producir eses cambios entre as dúas enquisas), os resultados son os mesmos, o que fala dunha interesante estabilidade das mostras de cara a darlles significación a outros datos das mesmas enquisas.

Tomamos como máis certos os datos do Postelectoral ao permitir esa nova opción, agora explícita, e podemos concluír que nese intre (2009: entre o 7 e o 31 de marzo) os datos eran os do Postelectoral que figuran na táboa 1.

Dese $50,3 \%$ dos enquisados que tiveron o galego como lingua inicial (e que a van perdendo por tramos de idades, como imos ver), cantos falan galego decotío? Segundo o IGE, na enquisa mencionada (ver nota 8), fálano o $30 \%$ da poboación igual ou maior de cinco anos, unha porcentaxe que será maior se a facemos

\footnotetext{
${ }^{10}$ Se non se di nada, os NC («Non contesta») van incluídos no cómputo (sempre é unha cifra anecdótica nesta clase de preguntas), figuren ou non as súas porcentaxes.
} 
só para os maiores de idade, que son dos que falan as enquisas do CIS xa citadas (o 5,5\% — - aproximadamente — está entre os 5 e os 17 anos no censo do 2008 na pirámide de poboación de Galicia), e iso quere dicir que a ese $30 \%$ hai que sumarlle (sempre aprox.) o 1,7\%, consecuencia da redución da base de cálculo da porcentaxe (agora é do 94,5\% esa base), e sendo así as antigas porcentaxes soben: quédanos un $31,7 \%$ de xente maior de idade que fala sempre galego, moitos menos dos que tiveron o galego como lingua inicial no conxunto da poboación maior de idade.

$\mathrm{Na}$ enquisa do Postelectoral do CIS podemos ver (gráfico 1) o declive coa idade da aprendizaxe do galego como primeira lingua:

- Gráfico 1

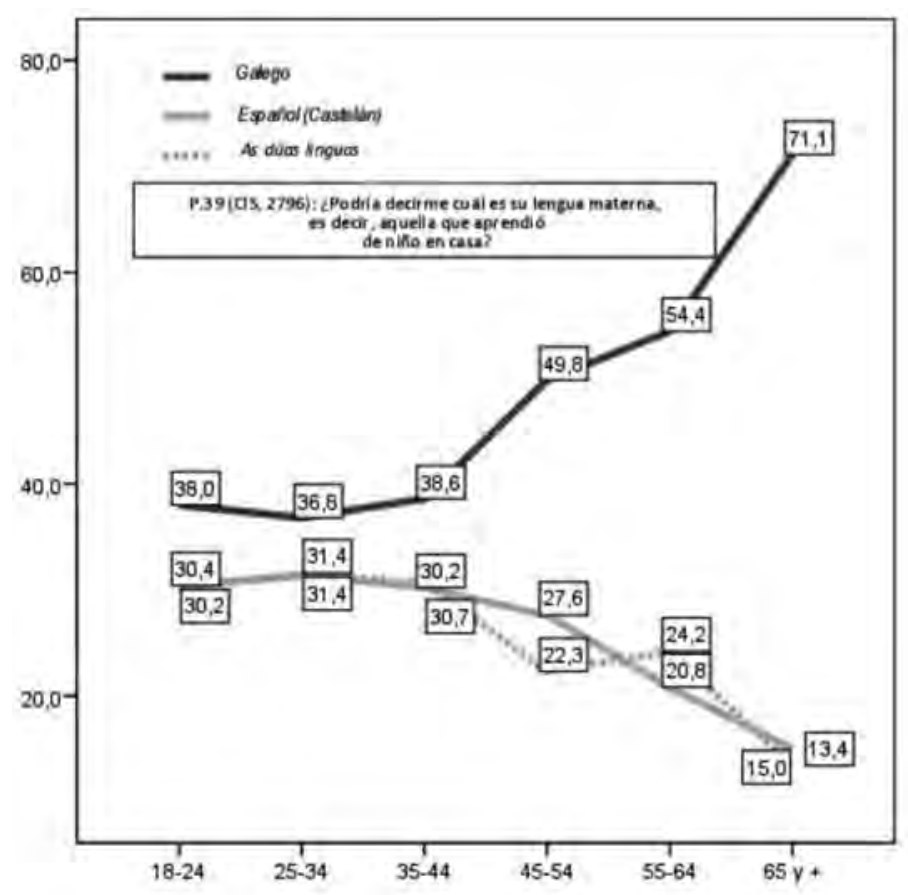

Tamén podemos ollar para o declive segundo o tamaño de hábitat (gráficos 2 e 3) na mesma enquisa do CIS, e traballar xa sen deixar de ter en conta as dúas variables quizais máis ameazantes para o galego, polo que amosan e polo que ocultan: 


\section{- Gráfico 2}
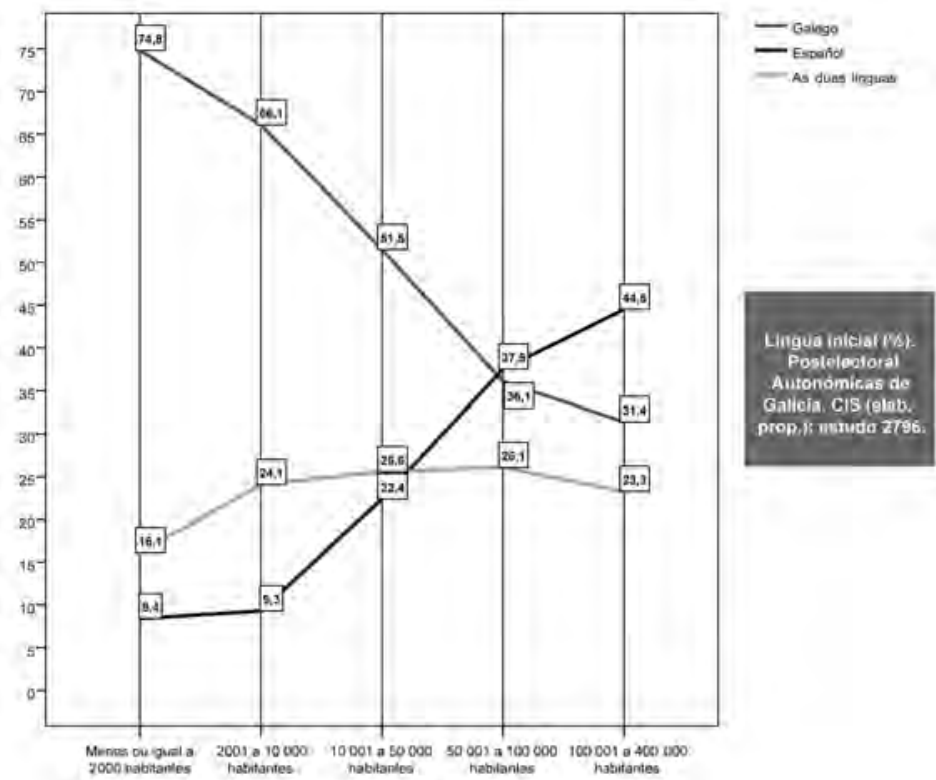

- Gráfico 3

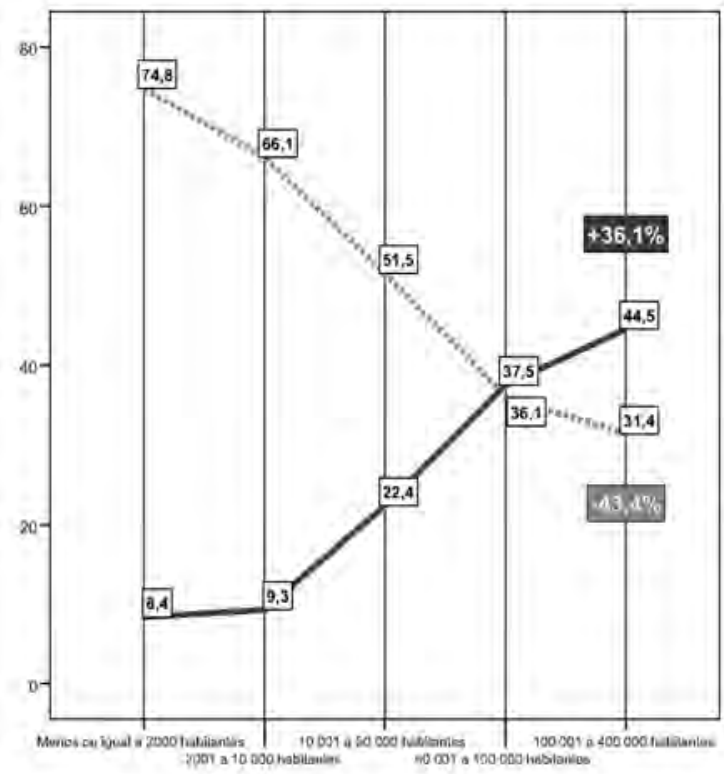

Trer Galego

- Espanol

\% Eingua inicial/Tamaño de hábitat.

Postelectoral

autonómicas 200

(CIS-elab.propia) 
A idade e o tamaño de hábitat teñen directamente que ver co declive do galego como lingua inicial e/ou como lingua falada decotío (sempre) e isto perfílaa como lingua declinante a unha velocidade histórica, quizais coa maior velocidade de perda que nunca chegou a ter. Talvez non paga a pena pórlles cifra ás proxeccións derivadas disto: o galego tería unha vida como lingua inicial duns 50 anos para ficar á fin deste proceso cun 5-10\% (rural, sobre todo) dos maiores de idade como falantes iniciais do galego, máis ou menos. Como falantes acotío (sempre) só ficarían algúns deses poucos da lingua inicial resistente. Claro, todo isto ceteris paribus, que non será así: a vontade, a política, a conciencia, a necesidade, os novos escenarios, a mesma economía poden mudar estas proxeccións e, sen dúbida, vannas mudar. Polo de agora, as cifras de caída de galegofalantes plenos do IGE-2008 son abraiantes, como se pode ver nos gráficos 4 e 5 (provincias 2003-2008 e totais 2003-2008). Algún especialista fala da posibilidade de que as cifras do IGE-2003 estean erradas. Todo é posible, pero non hai datos a prol diso e hai moitos a prol da realidade da caída forte do uso pleno da lingua.

- Gráfico 4

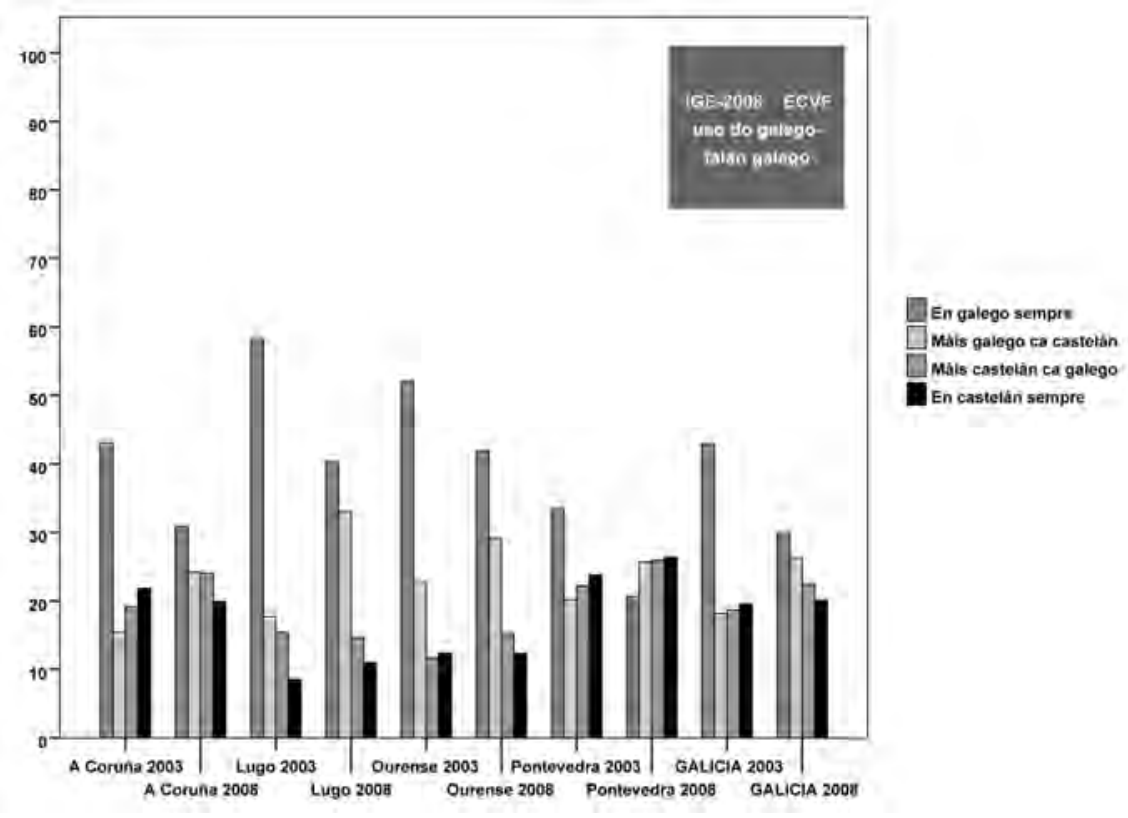


- Gráfico 5

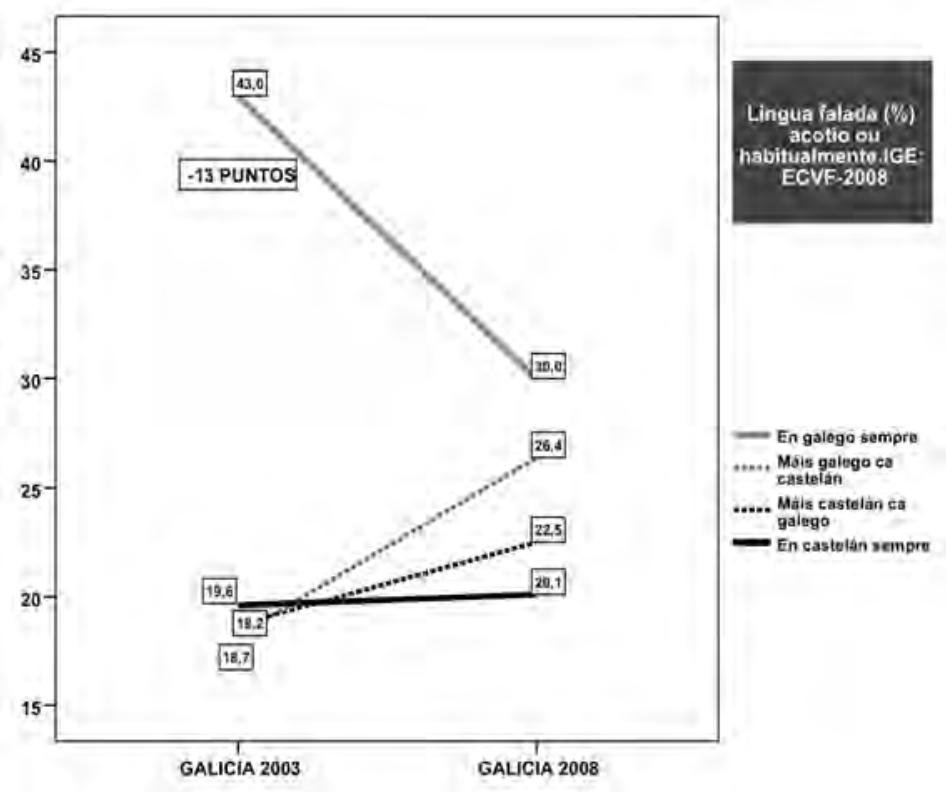

\section{O DIAGNÓSTICO DO GALEGO}

Con estes datos (puxen os mínimos posibles para non transformar este pequeno traballo nunha exposición de pintura gore e pasar á parte efectiva ou pragmática), é posible manter viva a nosa lingua?

Esa é a gran pregunta e aí hai que centrarse xa. O diagnóstico do galego está feito e ben feito, e se non fose así dou agora de novo a miña opinión como sociólogo: o galego carece de futuro como lingua viva nun prazo curto, pero tende a manterse como lingua morta para as falas familiares e intragrupais nas xeracións criadas no galego (declinantes) e nos círculos intelectuais e universitarios de Galicia (medrando aínda).

As proxeccións dos actuais datos, se non facemos entrar no cálculo as variables subxectivas ou non doadamente medibles (vontade crecente de falalo, crecemento da ilustración popular e das clases medias, vitoria electoral dunha 
maioría decidida a cambiar a rota de caída, etc.), son así de negativas e non se ve ningunha muda da tendencia.

Se houbese tan graves erros de método no IGE (ou no CIS), as cousas cambiarían, pero non semella probable que iso veña de pasar de xeito relevante. A percepción subxectiva da xente da rúa, polo que eu podo sinxelamente observar, a xeito de antropólogo de ocasión, é moito peor ca os datos estatísticos.

En liñas xerais e con certos matices, veño a coincidir coa maioría dos lingüistas e sociólogos galegos, aos que podemos ler no portal de sociolingüística do Consello da Cultura Galega, xa mencionado, que son excelentes para tomar un contacto rigoroso co problema. Estudosos como Henrique Monteagudo, Francisco Fernández Rei ou Mauro Fernández, e tantos outros que coñezo menos (incorporeime tarde á análise do problema, e só co obxectivo de achegar a miña experiencia como sociólogo, non como sociolingüista), marcan unha relevante liña de traballo.

Hai, quizais, un pesimismo en Galicia moi moderado polo medo a que a súa difusión faga aínda máis dano á lingua. Non será así: só o coñecemento pleno da situación pode facer posibles as estratexias recuperacionistas. Se a xente non é consciente da gravidade da situación non colaborará na súa muda.

O factor político estase a amosar moi importante. Ata agora non tivemos moito en conta este factor, pero agora si debemos telo por diversas razóns recentes que paso a enumerar e que son dignas de matinación. Pero tamén factores sociolóxicos e psicognitivos deben ter que ver coa situación:

1.- O cambio producido na evolución do PP cara á cuestión lingüistica dende os vellos tempos de Fraga e aínda antes, como é sabido: as políticas restritivas de Feijóo cara ao galego, apoiadas nunha minoría social moi pouco amiga da nosa lingua e que pon por riba da recuperación da lingua propia a liberdade dos pais (no ensino) para elixir a lingua chamada "común», alén das leis e dos costumes, e mesmo do sentido común, deixan no desamparo o galego no ensino infantil e medio nas grandes urbes, onde ten maiores problemas para sobrevivir. En setembro de 2010 soubemos (polo Sindicato de Traballadoras e Traballadores do Ensino de Galiza [STEG]) que o 40\% (aprox.) dos pais urbanos (sete cidades) elixen o galego como lingua infantil: ben, pois o decreto non permitirá que eses pais cumpran os seus desexos. A cifra do $40 \%$ é importante e fala dunha certa recuperación da conciencia da lingua propia. É un dato ben positivo. 
2.- A vitoria do PP nas eleccións autonómicas de 2009, que lle permite aplicar as súas políticas, xa anunciadas moitas veces e visualizadas cando os seus líderes foron a unha manifestación da organización Galicia Bilingüe, a máis activa das organizacións pouco amigas de feito da recuperación do galego, que se apoian ás veces nun xeito de neoliberalismo lingüístico que, nalgúns casos, chega a usar a vella expresión se está de morrer que morra ${ }^{11}$.

3.- Os súpetos procesos de urbanización de Galicia nos últimos decenios ${ }^{12}$, que puxeron a moita xente diante da necesidade de deixar de lado o galego como lingua entendida como ineficiente para a vida urbana e social (e reforzada a crenza na vida decotío), xente que deixará de ter o galego como lingua inicial para os descendentes ao tempo que o idioma vai quedando como lingua de familia, exclusivamente.

4.- $A$ actividade antilingua de novos grupos politicos e dos medios máis centrais (en particular UPyD e os novos medios extremadamente activos neste tema: Intereconomía, Libertad Digital, etc.) que fan da loita contra as linguas periféricas un xeito de obter votos e apoios entre a xente máis contraria á recuperación lingüística, ao tempo que consolidan unha idea unitarista do Reino de España que ía en declive dende a democracia.

5.- Xa que logo, a politización da cuestión lingüistica, que lles resta apoios ás linguas periféricas entre a xente que vota a partidos centrais, sobre todo o PP e UPyD, ao tempo que fai do factor «lingua» unha cuestión desa clase, electoral e política.

6.- A centralidade do tema da crise e o desemprego entre os temas relevantes da axenda pública, que marxina o tema da lingua e o afasta da primeira plana dos medios e da axenda mediática no momento en que Galicia sofre unha actividade negativa do xeito xa citado.

7.- A idea hiper-optimista de que o galego non pode morrer como lingua viva, espallada dabondo, mesmo na Galicia crítica. De feito, o galego está baixando falantes a unha velocidade descoñecida.

${ }^{11}$ R. Vilas: «Y si desaparece el gallego qué?», Libertad Digital, 21/10/2009: http://www.libertaddigital.com/opinion/raul-vilas/y-si-desaparece-el-gallego-que-51442/

${ }^{12}$ A. Precedo, A. Míguez, M. I. Fernández: «Galicia: el tránsito hacia una sociedad urbana en el contexto de la Unión Europea», Revista Galega de Economía, vol. 17, número extraordinario (2008). 
8.- A idea absurda e incontrastable de que o galego-persoa ten unha complexa relación co galego-lingua, o que explicaría a aparencia de morte, cando non é así: só serían xeitos peculiares dos galegos como pobo, que ás veces fan cousas raras, como non falar o galego.

9.- A idea normativo-sociolóxica de que ou ben a lingua, en xeral, non ten nada que ver coa economía (formas do espírito), ou ben ten que ver, de xeito non evitable, para mal no caso do galego: lingua rural, imposible como lingua urbana e de oportunidade. Negación do galego como lingua de modernidade e de progreso.

10.- A idea de que sempre hai tempo para recuperar a lingua propia, porque sempre está aí, latente.

11.- A idea de que a lingua galega é exclusivamente un luxo cultural que non paga a pena manter (e isto conecta co punto 9), idea esta moi típica da pequena burguesía urbana pouco ilustrada pero moi importante e activa como clase entre as clases populares e as clases medias.

Estas ideas e feitos, e moitos outros que podiamos salientar, son unha teimosa e negativa presión sobre a lingua propia de Galicia, que se vai mantendo a forza de voluntarismo e de urbanización demográfica aínda insuficiente, nalgunha medida cada vez menor.

As dificultades de chegar a acordos co actual goberno da Xunta de Galicia fan máis preciso ca nunca o deseño de estratexias de futuro para afrontar a recuperación do galego con algunha esperanza de éxito. As estratexias de recuperación son a cuestión menos doada de todo isto, e reclaman unha creatividade ao servizo do galego, a posta en común de ideas, a realización de encontros nesta liña, pensando sempre en reintroducir a lingua tendo en conta as cuestións obxectivas que a están facendo desaparecer e as cuestións subxectivas que determinan as crenzas xerais e populares sobre todo isto.

\section{OS PROXECTOS RECUPERACIONISTAS NO FUTURO DO GALEGO}

As estratexias de recuperación da lingua (sempre garantindo o castelán como idioma que hai que aprender se alguén non o ten aprendido, cousa que é extremadamente rara no medio urbano de Galicia) terían que considerar, un por un, eses e outros puntos negativos posibles e traducilos en acción positiva, o que non 
sempre é doado: as tentacións máis claras e extremas son ben a do amolecemento en nome de quen sabe qué datos mal interpretados de xeito erradamente optimista ou ben o sectarismo ao que nos pode levar unha certa desesperanza que nos afasta da xente.

Podiamos comezar a ordenar estratexias para levar adiante. Estas e/ou outras, a modo de suxestión:

1.- Reintroducir a lingua galega entre os problemas que os galegos poñen na axenda pública, o que quere dicir que é preciso espallar a situación real da lingua e a necesidade de defendela, pero non por antollo cultural, senón por necesidade económica. Neste sentido, é preciso non deixar de investigar, falar e debater do tema. O silencio é a morte.

2.- Reintroducir o galego, cando falte, na axenda mediática, o que debe de levarnos a facer dos medios un altofalante da lingua.

3.- Promover un pacto lingüistico entre os principais partidos, co PP incluído, o que permitiría, de facerse, traballar fóra da excesiva perspectiva política en que hoxe anda a moverse o tema da lingua.

4.- Impulsar o uso do galego nas cidades, na liña dese positivo $40 \%$ de pais que o piden para os seus fillos: novos medios, internet, actos, cultura visual en galego, música... O mundo do galego como un mundo moderno e de futuro.

5.- Apoiarse de xeito especial nas novas clases medias emerxentes, novas profesións, novos modelos vitais, xuventude activa, etc. É nestes sectores onde o galego se pode asentar máis doadamente no seu regreso á cidade.

6.- Reintroducir o galego no mundo empresarial, comercial, financeiro e de servizos, e fuxir así de calquera opción de presión ilexítima.

7.- Ir cara á idea de que o español é unha lingua franca para todos os habitantes do Reino de España, pero a lingua propia, segundo a historia e a lei, é o galego, lingua que ha ser democraticamente (libremente) prioritaria na comunicación interpersoal e nas demais comunicacións para que poida seguir viva.

8.- Ir cara á idea de que a vida do galego non é só a vida dunha lingua: é a vida dunha cultura e dun pobo. Tamén é a súa dignidade e o seu orgullo. Perdelo é perdermos.

9.- Artellar iniciativas para servir a vontade de socializar os fillos en galego alí onde non haxa esas posibilidades: creación de escolas mancomunadas, centros culturais, etc. 
10.- Ir contra as rutinas e impulsar a creatividade dos activistas da lingua: erguer algo así como «todos os días unha idea para defender a nosa lingua».

11.- Loitar contra o noso propio sectarismo, se é que o temos, porque iso é letal para a vida do galego.

E mil ideas máis para o galego, máis necesitado ca nunca de acción eficiente.

\section{ALGÚNS DATOS BÁSICOS PARA AS ESTRATEXIAS DE RECUPERACIÓN}

Hai unha antiga crenza entre os activistas da lingua galega sobre a defensa do galego polas clases populares que non é de todo certa: as clases populares, que fóra das cidades grandes de Galicia falan máis o galego (e iso fixo que o galego se mantivese durante os últimos séculos), non son as que máis o defenden, e isto é lóxico e normal, pois son as clases populares as que foron impulsadas pola historia e polos de arriba a identificaren o galego coa miseria rural fronte ao poder económico das vilas e cidades, que xa ían asumindo o castelán, e fronte ao poder do Estado, que fixo do castelán a lingua única da Administración. Ao iren facendo propia esta última crenza arredor da identificación galego / pobreza / atraso / ruralidade, as clases populares vanse ir preparando para a inmigración interior coa idea de que unha vez posto o pé fóra da aldea o galego hai que deixalo nela.

A táboa 2 amósanos o cruzamento que enuncia o título (clase / xuízo comparativo Bipartito / PP), e nela pode verse como as novas clases medias e as clases altas teñen unha posición máis preto do Bipartito nesta cuestión, que é rexeitado polas vellas clases medias, sobre todo (boa parte das vellas clases medias familiares, non as novas clases medias emerxentes nin unha parte importante das clases altas de vangarda, empresarial ou comercial, pero si sectores populares sen gran formación que actúan coa crenza de que o galego é unha lingua atrasada e inútil). Xa veño teimando nesta cuestión e nas que seguen en diversas publicacións porque é ben importante tela en conta: as clases máis modernas non desbotan falar o galego e amosan unha posición moi interesante. É case unha demanda que están a realizar os activistas da lingua: que lles dean xeitos e camiños. Velaí o traballo que hai que facer. 
- Táboa $2^{13}$

\section{(Lingua galega) (\%)}

¿En el tema de la lengua gallega cree Ud. que si hubiera estado el PP en el gobierno de la Xunta durante la legislatura anterior lo habría hecho mejor, igual o peor? (CIS, Postelectoral 2009, Galicia)

\begin{tabular}{llllllll}
$\begin{array}{l}\text { Status / Xuízo } \\
\text { retrospectivo }\end{array}$ & Mellor & Igual & Peor & N. S. & N. C. & $\begin{array}{l}\% \text { de presenza } \\
\text { da clase / status }\end{array}$ \\
\hline Clase alta / media-alta & 20,5 & 29,8 & $\mathbf{3 6 , 2}$ & 12,7 & 0,7 & 14,1 \\
\hline Novas clases medias & 21,4 & 34,8 & $\mathbf{2 9 , 9}$ & 13,9 & 0,0 & 19 \\
\hline Vellas clases medias & 25,4 & 30,1 & 16,5 & 27,6 & 0,3 & 21,9 \\
\hline Obreiros cualificados & 22,4 & 32,9 & 22,2 & 21,8 & 0,8 & 34,3 \\
\hline Obreiros non cualificados & 22,0 & 32,4 & 24,6 & 20,1 & 1,0 & 10,6 \\
\hline TOTAIS & 22,6 & 32,2 & 24,6 & 20,1 & 0,6 & Ata 100 \\
\hline
\end{tabular}

Nas táboas 3 e 4 podemos ver a relación dos votantes de cada partido segundo a súa lingua inicial e vemos aí como o PP é o partido máis galego-inicial, o que quizais nos indique que tamén é o partido máis rural, seguindo as hipóteses anteriores e, xa que logo, o que máis fala e, ao mesmo tempo, rexeita o galego, seguindo tamén as hipóteses fundadas que vou seguindo. Deste xeito, e como paradoxo, o partido que nesta xeira semella máis desapegado do galego é o que ten, sobre todo, que modificar as crenzas fondas dos seus votantes. Velaí o traballo da dereita galega sobre si mesma.

${ }^{13}$ É complexo pero é preciso dar algunhas explicacións para quen guste destas cousas: na construción da variable «status socioeconómico» (que é bastante intuitiva, a pesar da súa complexidade de construción), o CIS, a partir da variable «ocupación» (do propio CIS a partir tamén da Clasificación Nacional de Ocupaciones 1994 [CNO-1994] do Instituto Nacional de Estadística [INE] e da Clasificación Nacional de Actividades Económicas 1993 [CNAE-1993]) e da variable «condición socioeconómica do INE (+inactivos)», o empresariado de diversa magnitude, sobre todo o pequeno empresariado, tanto urbano como rural e os directores de empresa e administracións públicas son considerados, maioritariamente, como «vellas clases medias", o mesmo que boa parte de directores e profesionais. Grandes empresarios, traballadores, técnicos ou xestores de alto nivel e cualificación son clases altas e medias altas, e os traballadores convencionais cualificados ou sen cualificar son "obreiros cualificados» e "obreiros non cualificados». A variable construída polo CIS chámase «status socioeconómico». 
- Táboas 3 e 4

(\%) Porcentaxes de lingua inicial por intención de voto / voto declarado nos estudos Pre- e Postelectorais do CIS-2009. É probable un cambio metodolóxico na pregunta entre o Pre- e o Postelectoral, pois parece que no segundo o entrevistador dá de xeito claro a opción de dúas linguas e isto explicaría a diferenza.

\begin{tabular}{llllllllllll}
$\begin{array}{l}\text { Lingua inicial } \\
\text { Preelectoral cIS-2783 }\end{array}$ & PP & PSdeG & BNG & IU-EU & UPyD & Outro & $\begin{array}{l}\text { En } \\
\text { branco }\end{array}$ & $\begin{array}{l}\text { Non } \\
\text { votaríáa }\end{array}$ & $\begin{array}{l}\text { Non } \\
\text { sabe } \\
\text { ánda }\end{array}$ & NC & TOTAL \\
\hline GALEGO & $\mathbf{6 2 , 3}$ & 53,0 & 59,0 & 40,0 & 33,3 & 33,3 & 45,7 & 50,9 & 55,3 & 53,8 & 55,6 \\
& $\%$ & $\%$ & $\%$ & $\%$ & $\%$ & $\%$ & $\%$ & $\%$ & $\%$ & $\%$ & $\%$ \\
\hline CASTELÁN (español) & 28,2 & 33,2 & 26,0 & 33,3 & 53,3 & 38,9 & 35,8 & 30,4 & 28,8 & 28,1 & 30,0 \\
& $\%$ & $\%$ & $\%$ & $\%$ & $\%$ & $\%$ & $\%$ & $\%$ & $\%$ & $\%$ & $\%$ \\
\hline AS DÚAS & 9,2 & 11,8 & 13,1 & 26,7 & 10,0 & 22,2 & 18,5 & 16,8 & 14,7 & 17,0 & 13,1 \\
& $\%$ & $\%$ & $\%$ & $\%$ & $\%$ & $\%$ & $\%$ & $\%$ & $\%$ & $\%$ & $\%$ \\
\hline OUTRAS & 0,1 & 1,9 & 1,6 &, 0 & 3,3 & 2,8 &, 0 & 1,9 & 1,0 & 1,0 & 1,2 \\
& $\%$ & $\%$ & $\%$ & $\%$ & $\%$ & $\%$ & $\%$ & $\%$ & $\%$ & $\%$ & $\%$ \\
\hline VOTO DE & 23,3 & 24,0 & 12,2 & 1,0 & 1,0 & 1,2 & 2,7 & 5,4 & 19,8 & 9,6 & 100,0 \\
CRUZAMENTO & $\%$ & $\%$ & $\%$ & $\%$ & $\%$ & $\%$ & $\%$ & $\%$ & $\%$ & $\%$ & $\%$ \\
\hline
\end{tabular}

\begin{tabular}{|c|c|c|c|c|c|c|c|c|c|c|}
\hline $\begin{array}{l}\text { Lingua inicial } \\
\text { Postelectoral CIs-2796 }\end{array}$ & PP & PSdeG & BNG & UPyD & $\begin{array}{l}\text { Terra } \\
\text { Galega }\end{array}$ & EU - IU & $\begin{array}{l}\text { Outros } \\
\text { partidos }\end{array}$ & $\begin{array}{l}\text { En } \\
\text { branco }\end{array}$ & $\mathrm{NC}$ & TOTAL \\
\hline \multirow[t]{2}{*}{ GALEGO } & 53,0 & 46,1 & 50,3 & 30,3 & 60,0 & 15,4 & 40,0 & 40,9 & 57,1 & 50,5 \\
\hline & $\%$ & $\%$ & $\%$ & $\%$ & $\%$ & $\%$ & $\%$ & $\%$ & $\%$ & $\%$ \\
\hline \multirow[t]{2}{*}{ CASTELÁN (español) } & 22,6 & 28,7 & 24,2 & 45,5 & 6,7 & 30,8 & 36,7 & 30,7 & 20,6 & 24,7 \\
\hline & $\%$ & $\%$ & $\%$ & $\%$ & $\%$ & $\%$ & $\%$ & $\%$ & $\%$ & $\%$ \\
\hline \multirow[t]{2}{*}{ AS DÚAS } & 23,7 & 24,9 & 25,5 & 24,2 & 33,3 & 50,0 & 23,3 & 28,4 & 22,1 & 24,4 \\
\hline & $\%$ & $\%$ & $\%$ & $\%$ & $\%$ & $\%$ & $\%$ & $\%$ & $\%$ & $\%$ \\
\hline \multirow[t]{2}{*}{ OUTRAS } & 6 &, 3 & 0 & 0 & , 0 & 3,8 & 0 & 0 &, 2 &, 4 \\
\hline & $\%$ & $\%$ & $\%$ & $\%$ & $\%$ & $\%$ & $\%$ & $\%$ & $\%$ & $\%$ \\
\hline VOTO DE & 37,5 & 25,0 & 12,2 & 1,3 & 6 & 1,0 & 1,2 & 3,5 & 17,8 & 100,0 \\
\hline CRUZAMENTO & $\%$ & $\%$ & $\%$ & $\%$ & $\%$ & $\%$ & $\%$ & $\%$ & $\%$ & $\%$ \\
\hline
\end{tabular}


Algunhas destas cousas foron observadas con outros datos por sociolingüistas, filólogos e/ou historiadores galegos, e os traballos de Ramón Villares, Henrique Monteagudo, Francisco Fernández Rei, Mauro Fernández, Antón Santamarina, Ramón Lorenzo, Celso Álvarez Cáccamo e outros non menos relevantes están no fondo desta miña exposición, que é a dun sociólogo que se move nos ámbitos da comunicación política e a opinión pública. Dende esa perspectiva e tomando como referencia o conxunto do meu discurso público sobre a nosa lingua (Blog El voto con botas ${ }^{14}$, diario El Pais-Galicia ${ }^{15}$, revista Tempos Novos ${ }^{16}$, etc.), deixo este artigo a xeito de coda. Agora abordo a miña derradeira matinación como fin deste pequeno traballo.

\section{OS PRIMEIROS FROITOS DUN ANO INESQUECIBLE}

Foi inesquecible para min, sen dúbida, porque retornei á miña terra e ata fun agasallado co Pedrón de Honra e Louvanza, o que me enche de boas vibracións, que di agora a xente nova. Pero máis aló da miña vaidade, que non é pouca (mal cristián que debo ser), o que é realmente inesquecible é a emoción de ver a tanta xente na rúa loitando pola lingua, sentir a tanta xente aquí e acolá na mesma onda, ver como é posible pensar nunha Galicia outra e pensala coa maior parte dos seus habitantes puxando por ela. Quedan moitas cousas por facer e moito que loitar, pero as organizacións da lingua (todas elas, pero "Queremos Galego» é salientable pola súa capacidade de mobilización e de unidade) e as institucións (Real Academia Galega, Consello da Cultura Galega, sobre todo) están dispostas. Non faltaron algunhas voces públicas do PP a favor dun cambio no tema da lingua, fronte ao decreto chamado do plurilingüismo, nin faltaron moitas voces privadas desa mesma liña que amosaban a súa solidariedade coa mesma lingua. Como ten que ser. Un ano que fecundou hai pouco, e remato eu xa estas liñas, no intre en que souben, polo sindicato STEG, que a media dos pais que pediran o galego na educación infantil dos nenos nas cidades grandes de Galicia (as sete)

\footnotetext{
${ }^{14}$ http://votoconbotas.trincheradigital.com/

${ }^{15}$ http://ccaa.elpais.com/ccaa/galicia.html

16 http://www.temposdixital.com/
} 
andaba arredor do $40 \%$ (só un 13\% de galegofalantes preferentes nas sete cidades, como media). Isto non só é unha gran nova, é tamén, quizais, un punto de inflexión ou muda de tendencia se sabemos seguir avanzando, dando confianza, saber e forza, así como organización, aos pais que desexen o galego alí onde periga máis: nas grandes cidades e vilas.

Como sociólogo, e mirando os gráficos de tendencia, teño que dicir que só cun gran pulo e unha gran vontade o noso pobo poderá conservar a súa lingua propia. É unha batalla longa e non doada na que a intelixencia conta tanto como a vontade de facer. 